\title{
BUSINESS AS USUAL IN THE FEMINIST CLASSROOM?
}

Janet Delwiche, award winner

Vision. 'For now we see through a glass, darkly.'

1 Corinthians 13:12

LATE AUGUST, 1985. Twenty or so collegians-male and female, most white and female, two black women among them-convene for section 45 of Rhetoric 10:1. Enter their nervous, white, female instructor. A greenhorn, me. Calling roll, I do an involuntary doubletake, noticing that one of those black women must be ten plus years my senior. Disorientation . . . and relief? My contact with black women has been slight. Not until graduate school had I actually shared a classroom with one. My undergraduate university in Wisconsin was small, insular; but didn't I manage to cultivate a few "working" friendships with black women even there? With Crystal and Alice, the two black receptionists who scheduled my tutorials at the writing center and, incidentally, shocked me during black history month by insisting that yes, sadly, the racism on Whitewater's campus was ravenous. But racism in my class? Never happen. I won't let it. Besides, it's the eighties and well-known that the University of Iowa is a cosmopolitan, liberal institution - here $I$ am, after all. The daughter of a truck driver and waitress, the only kid who made it to college, enrolled in a Ph.D. program to boot. My blue collar roots made me sensitive to class bias (how long it took me to stop saying "I should have went"!), and confident that a little aptitude and persistence really could make the swim up mainstream possible. And sexism? That went out with the sixties and bra-burning. Today we have things like Affirmative Action and Equal Opportunity Grants to ensure that women and blacks $d o$ get equal access to the fruits of higher education. Weren't the bodies in my classroom--the majority female, two of them black-living testimony to this reality? Of course. Especially those white feminine faces before me, reflections of myself seven years 
ago . . . rivals? And the men. Why did I secretly wish there were a greater proportion of them? Pushing such thoughts aside, I decide that here is diversity enough. Just enough to foster lively discussion as we unite in the overriding purpose to develop skills in reading, speaking, and writing.

"This is a course in communication," I announce. Commune we will, I think to myself. Soon I'll have them fervent with the desire to question, to explore, to learn from each other. Our classroom will be fluid, compassionate, womb-like-one of cooperation and warmth, of ebullient support for one another. Soon they'll be tapping the rich sources of knowledge within themselves, the fecund ground of personal experience upon which to build. I'll help them discover spaces too many of my own college teachers deemed unworthy of exploration. Together, we'll examine such spaces with sensitivity and vigorous intellect. Gradually, my role as teacher and authority will evaporate while all learn to revel in the freedom to know oneself as the sine qua non for making sense of the world. Never will we be plagued with awful silences since each will be eager to bring his or her unique insights and experience to the reading or topic at hand. Especially since I'll dispel early the fallacy that I, as teacher, alone possess the "right" readings and answers.

"And most importantly, perhaps," I continue, "this is your course." Important to qualify terms straight away. Independent thinking might be a new concept for just a few of them. "You've all had practice in reading, speaking, and writing, and I'll be inviting you to draw upon that experience to identify, for yourselves and each other, your strengths and weaknesses, to suggest ways we can go about refining such skills." There. Such was my bold, assertive gesture to be genuinely student-centered, to validate their expertise as communicators. Did it end there? For as I spoke, I was passing out the departmental brochure and my very detailed course policy. (Well, even the womb of my classroom must have some parameters, an elastic, amniotic membrane through which we might burst now and then.) Had they heard me amidst the rustling of paper?

"Now, let's form a circle and begin to get to know each other," I suggest (I command?), thinking my presence might be effectually reduced to but one voice in the multivalent dialogue I am about to encourage. "Let's go around the circle and tell something about ourselves-name, hometown, major, interests-anything you care to share. Who'd like to start?"

Blank stares, lolling heads, averted gazes. I notice that the older black woman has skewed her portion of the circle by turning the writing arm of her chair to the outside so that she has the option of 
looking at us or the wall-her focus of attention now. Why is she resisting my efforts to include everyone in this little theatre-in-theround? It begins to dawn on me that the light bit of stage-managing I had envisioned as a pleasant invitation to communicate is fast becoming an act of coercion. Reluctantly, I fall back into "conventional" classroom dynamics and take the lead. Already sick of my own voice and uncomfortably aware that no one else in the room has said a public word as yet, I begin the series of self-introductions. Will every day require such awkward prodding? Am I the only one interested in true dialogue?

We do manage to get around the circle, a few native Iowans forming early bonds based on proximity of hometowns, a few co-eds on the coincidence that they happen to live in the same dorm. Well, here's something, I think to myself. Community or clique-formation? Too early to tell. Before dismissing, I explain that tomorrow will bring another invitation to communicate: an in-class writing in which they describe a significant experience involving reading, speaking, or writing. This is a departmental mandate, a diagnostic exercise which will allow instructors to detect early those remedial students who managed to slip past the ACT and through registration. This diagnostic tells me much more about the students I'm working with than their relative levels of fluency.

Look not at visions, but at realities.

$$
\text { -Edith Wharton }
$$

One student recalls with anger his spending two weeks of nights at the local library working on a term paper. The final product comes back red-marked with a grade of $C$-. Meanwhile, his classmate spends merely a few hours the night before and secures a $D+$. "Never," concludes John, "will I waste that much time on a paper again. Why should I when somebody who doesn't put near the amount of work into it gets almost the same grade as me?" I know the feeling. Competition starts early. Why is it that I, too, continue to experience the frustration at having learned more from the research and process of writing on a topic than the final product succeeds in conveying to the instructor?

Another student hopes that she'll not have to write on stupid topics like "what I did on summer vacation." I wince, feeling less assured that my plan to assign an essay on a meaningful event as an early writing exercise will be a hit. Wendy would rather improve her skills in business writing, though she neglects to mention with any specificity what kind of writing that is.

I'm shocked at the rather devious delight expressed by a male student describing a cat and mouse game he played with his high 
school speech teacher. Ed's principle for choosing speech topics is governed by what he believes will offend her the most. His method of delivery aims deliberately to let her know that he doesn't take the class seriously. As an afterthought, Ed insists that he and the "tough old broad" departed reconciled in spite of their semester-long battle. I wonder if his is a disposition only a mother could love, what games he'll elect to play with me.

The first enthusiastic experience with communication comes from a student who describes how she demonstrated cake-decorating for her high school speech class. It went so well, Cindy hopes she'll be able to repeat the performance in 10:1. I can't help chuckling as this so typically reflects a feminine enterprise. The account seems less funny to me when I consider that the young men in our class might well trivialize the value of her project should she deliver a presentation of this sort.

The next student writes that he doesn't remember doing any important papers or speeches in school, only reading stories that he never got. Given his choice, Jeff likes to read books by Stephen King. His favorite magazines are Hot Rod and Car and Driver. Maybe he could give a speech on how to sandblast a carburetor. I sigh. We'll have to talk about audience . . . soon!

A bit anxiously, I pick up the diagnostic written by Cherry, the older black woman who seemed suspicious of the circle of fellowship I attempted to create the day before. Her piece is by far the most moving, lucid prose to be found in the stack of papers I'm perusing. She tells of her desire, her need to write poetry amid the raising of three children, the fights with her husband, life in a Detroit ghetto. "Silly! Right?" she says, and then goes on to express her selfconsciousness, wondering what her classmates of eighteen or nineteen might think of a black, forty-plus-year-old woman sitting in a freshman Rhetoric class. She recalls her first return to school, a writing class in which the teacher singled her out in praise of some poems submitted as evidence of her craft. That was ten or fifteen years ago. This time she's determined to remain until her degree is completed.

$$
* * * * * * *
$$

\section{Myopia [Gk. myōps fr. myein to be closed + ōps eye, face]}

Above I have tried to recapture some of the impressions and frustrations, the idealism and doubt that surfaced throughout my first semester teaching freshman Rhetoric. The lack of awareness with which I sought to create a non-hierarchical, collaborative classroom, to abdicate my authority as teacher, now seems to me simple-minded and naive, however good the intentions and sometimes, the results. At the 
time, I did not act out of what one would call a specifically feminist consciousness. I merely operated according to the lessons that many years in the classroom as student had taught me: that learning is most exhilarating when the teacher refrains from posturing herself as expert and sole possessor of knowledge and allows students the space and time to arrive at truths about the world themselves. Why then, I wondered, did my students seem uncomfortable with, often reject the autonomy I strived so earnestly to grant them? Why during our supposedly open discussions would silences occur with greater regularity than desired? Why, when I invited them to explore their interests and experiences, would they cross-examine me for particulars on exactly what $I$ wanted?

What I had forgotten in becoming a teacher myself and what feminist theory has lately helped me to remember is that the habit of questioning authority, of assuming the legitimacy of one's own thoughts and experience is not a lesson most of us come to college having already learned. Reflecting on that first semester of teaching with the hindsight of a raised feminist consciousness, I must acknowledge that both my students and I were daily bringing "texts"1 other than The Little, Brown Reader to class; such "texts" brand us as male and female, teacher and student, and are laden with the values of a capitalistic, sexist, and racist society. They comprise the hidden agenda that informs what my students say beyond content and writing ability in the diagnostic exercise I've described. These (pre)texts die hard, if ever, and help explain why, despite my efforts to present myself as a thinking, feeling partner in communication, a few of my student evaluations suggested that I "take more control," "try not to show my emotions so much," and "treat the students more like adults."

Perhaps the most important thing I have learned as teacher of a mixed classroom and student of feminist thought is that hereafter I must take into account what Susan Stanford Friedman calls "the lens of gender as it operates in classroom dynamics and pedagogy."2 Convinced as I am that this will help cure the myopia that kept me from seeing how gender affects the flow of communication in the classroom, I can work with greater success toward creating an atmosphere that is non-hierarchical, interactive, and vital.

Much has been written on the "highly charged arenas of inquiry"3 of Women's Studies and feminist courses, on the chaos that frequently erupts there. Not enough has been said concerning courses which do not take women's writing or issues specifically for their content but have much to gain from feminist styles of teaching. Freshman Rhetoric is one such course. While Women's Studies courses usually 
attract students with some prior interest or sensibility attached to the condition of being female and/or oppressed, those of us who teach mainstream courses meet with a greater proportion of students who are gender, race, or class biased and unabashedly complicitous with the values and structures of dominant culture. In espousing the principles of feminist pedagogy-cooperative as opposed to competitive structures; the legitimacy of life experience; a concern with the process as well as the product of learning; a commitment to changing attitudes toward women-to name the most frequently discussed, those of us who seek to act upon such tenets in mainstream classrooms are doubly beset since many of our students might interpret explicit avowals of feminist perspectives and methods as oppressive to the values and ways of doing things they hold in common with patriarchal society. Similarly, the departments under which we work might view our teaching styles and philosophies as impertinent or incommensurate with the goals of the courses we happen to teach. The feminist teacher seeking to dismantle the frameworks which constrain her to teach certain contents from certain perspectives only owes it to herself and to her students to examine such dicta and ask, finally, who they serve.

Such speech threatens the very basis of the cultural currency. As woman begins to speak a discourse no longer defined and limited by the patriarchal inscription, Eve's voice recovers its intrinsic value.

\section{-Christine Froula}

I begin this essay in an autobiographical mode akin to the uncanonized texts composed of women's diaries, journals, letters and to the testimonials that, within the past fifteen years or so, have begun to flavor the pages of scholarly publications devoted to feminist theory and pedagogy. Such a trend speaks loudly the effort to validate women's experience as a basis for challenging the values and universal applicability of theories generated by the dominant, patrocentric culture as well as the teaching practices which serve to perpetuate behavior and thinking that legitimizes the bourgeois, white, and male. ${ }^{4}$ Central to the women's movement in toto and to feminist pedagogy in particular is the question of authority and its maintenance within a society upholding structures that are hierarchical and oppressive.

Feminist thinkers who seek to connect the issue of authority inside the classroom to its manifestations outside often cite capitalism as the infrastructure upon which higher education is built. Within my own survey of writings on feminist pedagogy, I hear a chorus of voices united in a radical analysis of the American university and its role in the capitalistic system. Asserting that academia mirrors corporate structure, Sally Miller Gearhart notes that "Higher education is, after 
all, in the business of producing professionals," that "the academy is the primary training ground for the personnel of an oppressive society." Echoes Ann Ferguson, "academic discipline and legitimation through credentialing serve[s] the capitalist economy by producing a docile work force and channeling students into class-related jobs." And in an analysis of Disorders in Higher Education (a discussion made possible by the Ford Foundation, Exxon, IBM, and AT\&T), Michael Ryan deconstructs purported concepts of "reasonableness" and "integrity," revealing them as value-laden and ideologically biased, as "simply the benign face of power, coercion, and the everyday brutality of patriarchal capitalism in America."7

We live in a society based on exchange and competition for limited resources that enable advancement and power. In the world of high-level government and business, law-makers and captains of industry hold cultural currency and capital, own power and the means of distributing it. In a traditional classroom, the word-giving and truth-saying teacher owns knowledge and dispenses it to students. The economy of such classrooms makes them places where mere transferrals of information nullify inquiry, where students pay to absorb the teacher's knowledge, where teachers hold students responsible for producing papers and correct answers on tests. Wages accumulate in the form of grades and credits; transcripts and diplomas secure white-collar jobs.

In his Pedagogy of the Oppressed, Paulo Freire metaphorically describes this exchange of "goods" as the "banking" concept of education. ${ }^{8}$ Though Freire himself never mentions women in his influential account of how conventional education is an exercise in domination, feminist educators remain, understandably, indebted to his work in seeking to construct their own pedagogies and revolutionize their own classrooms. What Freire has helped us see is that, essentially, students have much in common with women and oppressed people. Just as traditional education projects ignorance upon the student, so women's work, lives, and experiences are trivialized and systematically devalued by our culture. In the patriarchal settings of our boardrooms and classrooms, women and students are positioned as objects, denied the right to think and speak as subjects. The situation is particularly distressing in regard to female students. Discussing the myth of co-education and how male-derived norms of the classroom serve to silence females, Francis Maher notes that while masculine modes of speech elicit approval of men for being "assertive" and "forceful," the tentativeness and questioning tone of women's comments are usually taken less seriously by teachers. ${ }^{9}$ It becomes, for Maher, a matter of interpretation since we might read such "feminine" styles of partici- 
pation not as non-assertive, weak, and hesitant but rather, as cooperative and constructive, as announcing a respect for other points of view by encouraging the next speaker to elaborate.

Elizabeth Spelman offers other possible meanings for the silence and relative passivity of women students, one of which seems especially pertinent to the position of women within the context of institutions that prepare them to enter the professional world of men: "What they want from college is a big boost in the direction of a lucrative career, and they would prefer to have their college days be as free of pain and self-reflection as possible." ${ }^{10}$ Such indifference is symptomatic of a generation of young women who don't want to hear that opportunity is unequal. Rather than question what they're taught and how, students want to know what they have to do to pass the course, get degrees and impress future employers. Given the values and incentives provided by our culture, small wonder that too many students are content to be the passive receptacle of received wisdom. For, as social beings, we have learned that the rewards are great when we follow instructions given by parents, teachers, and later, bosses.

What is the answer? . . In that case, what is the question?

-Gertrude Stein (Last words. From Sutherland's A Biography of Her Work.)

Feminist pedagogy has been growing up alongside and refining reform education just as feminist theory continues to appropriate and transform critical tools and methods of semiotics, reception theory, psychoanalysis, deconstruction, Marxism (and so the list goes on) to challenge the purported value-free, objective, positivistic claims to Truth and Knowledge. Since feminist critics have taken the bold step toward revealing monolithic theories that flatten out or ignore the validity of women's experience as strategies of male hegemony, feminist teachers must make good and continue this work by breaking norms of classroom dynamics which marginalize students' voices and suppress independent thinking. The task, then, is none other than to deconstruct the oppressive social texts that keep our vision dimmed, our voices muted, our opportunities to think and act as autonomous human beings unequal. As educators intent upon changing the world, we must foster in our classrooms a more complex and evolving view of reality than dichotomies such as male/female, student/teacher, master/slave, right/wrong allow us to. We might begin to burst the mind-forged manacles of such categories by adopting, with Freire, a concept of our students as conscious beings by encouraging them "to perceive critically the way they exist in the world." 1

In his concept of "problem-posing" education, Freire stresses the need to replace the situation of dominance that characterizes the 
"banking" approach with a relationship between teacher and student that is dialogical. With our students (rather than over and above them) we pose questions, open up what is determined, and become coinvestigators of a world which is not static, but changing and evolutionary. In viewing the world as an uncompleted reality, problemposing education affirms the process of becoming and roots itself in the dynamic present of the student. ${ }^{12}$ The notions of dialogue and process here are certainly not new to feminist thought. In their own right, Women's Studies and feminist courses have encouraged students to bring personal experience to bear upon subject-matter, to posit "self as inquirer," allowing them to become, as Francis Maher suggests, creators and constructors as well as learners of knowledge. ${ }^{13}$ The dialectic between self and material, according to Maher and others, enables the intersubjectivity of thinking subject and subject of study that makes the project of studying women's writing, lives, and history engaging and vital for women. For the gynocritic, ${ }^{14}$ the common condition of being female roots women's texts in the dynamic present of her own life in a way that the past and present texts of men rarely are. Perhaps this informs the urgency compelling us to recover women's history as recorded by women writing before and with us; thinking back through our mothers and ahead with our daughters permits us to name the common sources of our oppression as women and to act out of a consciousness enabling us to transform the future.

\section{Praxes: Toward Écritures Élèves}

What would become of logocentrism, of the great philosophical systems, of world order in general if the rock upon which they founded their church were to crumble? . . . Then all the stories would have to be told differently, the future would be incalculable, the historical forces would, will, change hands, bodies, another thinking, as yet not thinkable, will transform the functioning of all society.

- Hélène Cixous

The common experience that students in Women's Studies courses often share facilitates the chance to open dialogue that is multiplicitous, that mediates (even celebrates) differences which might otherwise divide and silence. To achieve this in the mixed classrooms of mainstream courses often requires that we work even more deliberately to disrupt established patterns of competition, habits of inferiority and passivity that marginalize certain voices and exaggerate our authority as teachers. Many of the strategies that have long been part of the tool-kit of feminist teaching have worked reasonably well within my freshman Rhetoric classes to create an atmosphere that is nonthreatening and interactive. Interpersonal activities, such as small- 
group discussions of readings and workshopping of papers and speeches, help quieter students gain the confidence to bring their voices to the center, and often result in bonding among students which stimulates a truer dialogue in class-wide discussion. Cooperative structures and group projects undermine competition and foster interdependence. Ideally, this may lead to the practice of having students draw upon their own knowledge and experience as the primary source of what counts as pertinent to the subject and goals at hand. I often have my class form groups to create and present to each other speech handbooks which are then duplicated for distribution. Throughout the term, we refer to the guidance they generated and evaluate speeches together according to their ideas on what makes an effective speech.

I also like to encourage participatory decision-making in order to diminish the hierarchical form of authority that conventionally defines my role as instructor. In a course like Rhetoric, which takes no specific content as the object of study but is designed instead to develop skills, students can suggest or vote on the readings that sound most interesting to them and help determine what kinds of speaking and writing exercises would benefit them most. Indeed, what I consider the most effective assignments are often based upon my students' advice on how to adapt projected activities to their needs and interests along with their feedback upon completion.

In a class devoted to communication, I found that the choice of reading material, whether for purposes of providing a common basis for discussion or a model of what constitutes good writing, can greatly enhance performance. Two indispensable criteria for selecting reading for use in freshman Rhetoric are one, that it somehow speak to their interests and experience, and two, that it be somewhat playful and compatible with their level of skill. Like feminist thinkers (and women in general), developing writers have a need to validate personal experience and will profit when such experience can be incorporated into what they study and write. Like many women writers (as well as, perhaps, even those who are relatively accomplished), novice writers are vulnerable to anxieties of authorship ${ }^{15}$ when their only models for "acceptable" academic prose are depersonalized, latinate, tight-laced arguments. Much of my own pleasure in reading feminist criticism comes from the autobiographical and confessional elements which announce that someone, usually a woman, is writing self-consciously from and about what she has lived. Strangely, I relish as much the swerves and irregularities as I do the playfulness and flourishes that deviate from the norms of mainstream criticism and gravitate toward the wild zone, ${ }^{16}$ if you will, of 
scholarly writing. Similarly, no small part of the pleasure (as well as the pain and dis-ease) I experience in writing this essay derives from the very qualities about it for which more conservative academics and readers would penalize me: from the freedom to follow out a path of thought at whim, to interrupt my argument with constant deferrals, to indulge in heavy-handed analogies and intertextualities, to open this paper with trajectory of experience hinting at more feminist issues than I could ever hope to give closure to if I sat down and wrote for the rest of my life-all this fun, for a change, as I get on with the business of "scholarly inquiry!"

As for my students, I invite and reward like experimentation and play within their writing. For me, nothing is more disappointing than sitting down with a stack of student papers, ninety-percent of which announce their conclusion in a one sentence-paragraph thesis that answers the question they are supposedly exploring. Much student writing, coming across my desk at least, is uninspired, predictable, too pat. And I think the reason why has to do with the way we've been taught to "package" information along with every other aspect of our lives in American culture. Like the texts which script our gender, race, and class, the formulas for "sound" academic writing are categorical, rigid, neat. Somewhere along the way, somebody (probably one who was male, white, and bearded, possibly Greek) always tells us that everything we write must have a beginning, middle, and end; so much the better, we're told (we tell our students?), when we can validate the claims of our ideas, affirm our thoughts by referring to authorities, sources of real knowledge. As most of us are well aware, the trauma of integrating outside sources gets even more frenetic in graduate school; before we can sit down and bring ourselves to a text in a new and original way, we must wade through piles of precious, published data that record what everybody else who has read the thing before us has thought about it. Pretty soon we've lost sight of the primary text, of the real art and how it spoke to us in an individual and unique way. Our papers come back with comments like "too derivative," "you forgot what this critic says," "you really didn't say anything new here." Thus, at least in literary studies, the rules for approaching a text send a mixed message: our training as researchers too frequently molds us into mere detectives and data-gatherers amid the annals of scholarship when, ultimately, our mission is to contribute something new. Encouraged to track down received wisdom on a particular text or problem, we find ourselves wrestling with masses of criticism which eventually end up, at worst, overshadowing our response to the text, or at best, relegated to an encyclopedic collection of footnotes. Yet the overriding task being to produce a new and original argument, we 
spend as much of our time in graduate school unlearning the way we're taught to write and think about anything, unlearning the habit of finding, as an end to inquiry, somebody whose name (so often a he) has gotten into print to validate our insights. In a day when publication is the key to securing academic employment, it's invigorating and promising to realize that women's writing offers a body of literature upon which we can practice our criticism without, conceivably, consulting what better than half the human race of scholars have said about it first-if they bothered, in fact, to say anything at all.

But back to our students: it's no wonder that, like us, they early cease to be independent thinkers and submit to the inferiority that education, pretending to the pursuit of truth, imposes upon us. As reform and feminist educators, we must continue to ask with our students, whose pursuit? whose truth? When they come to our classrooms programmed into thinking that the basic five-point essay, peppered with a few quotations and concluding with the introduction, serves any occasion, we must help them unlearn those treadmill models and discover the process of writing and thinking. I seek to break the norm by exposing my students to personal narratives, short stories, and poetry-discourse that goes somewhere besides back where it started. Then I have them write their own personal narratives, their own stories in which they experience change of some sort, in consciousness, value, belief. The results are usually appreciable; only then do I discern true beginnings and selfhoods in what they write. Granted, some of the essays that I get are less "well-made" than the formulaic constructs that might have earned them A's in high school, that earned $m e$ A's in high school and throughout much of my undergraduate career. True, some of their sentences are affected; they lack grace and eloquence. But I'm more engaged as a reader by the thought in embryo that struggles to take on new form, by those moments when verbal expectations are thwarted and something a little bit different is happening at the level of language. In short, I guess I'd rather hear an active, honest mind thinking on paper, even if it means I have to work a little harder to follow its curves, than glide through a dull rehearsal of clichés and safe expressions.

When we ask students to bring themselves into the process of writing and thinking, we ask them to take risks. In college, selfexploration is rarely invited, but when it is, the temptation to over-indulge in naming one's lived experience as a means of making sense of the world is great. My concern is what will happen to the student who takes the risk of bringing herself into her writing (and finds she enjoys it) after she leaves my classroom. What will happen when she walks into her American history class and is asked to write 
a paper, with a beginning, middle, and end, on the abolition of slavery and the American Civil War? If I have done my job, she'll have a hard time closing that topic because the war goes on. Or, perhaps, backsliding into her prior self-the one that works better in a traditional classroom-she'll begin that paper safely, explore the problem by deferring to the authority of her textbooks, and end it neatly, as a good student/girl should. As a fledgling scholar committed to feminist pedagogy, I find myself continually facing similar cruxes. Having chosen to work within the industry of academia, I must decide whether to study the literary history of marginalized, women writersat the risk of such work being trivialized by the many traditional English departments that still exist, by a host of prospective employers-or, to play it safe and confine my study to those canonized texts which, sadly, many still consider representative of "the Great [and only] Tradition." I must decide whether to write these well-made articles for submission to ELH and College English or those flawed, unresolved riddles for Sinister Wisdom and Radical Teacher. While the notion that our realities as students and women are processual and incomplete strikes me as extremely attractive and liberating, I must also acknowledge that such realities are made of compromises, practical consideration, political expediencies. As Virginia Woolf might put it, one must secure her guinea, her share of cultural currency before she can be empowered to spend it to advantage.

\section{NOTES}

1 I borrow the metaphor of "text" here from Margo Culley, et. al., "The Politics of Nurturance," Gendered Subjects: The Dynamics of Feminist Teaching, eds. Margo Culley and Catherine Portuges (Boston: Routledge and Kegan Paul, 1985), 15. The particular texts they examine are the gendered categories of affect and intellect and how these pose special problems for female teachers.

2 Susan Stanford Friedman, "Authority in the Feminist Classroom: A Contradiction in Terms?” Gendered Subjects, 206.

3 Culley, et. al., 11.

4 I feel obliged to qualify my use of the expression "bourgeois, white, and male"especially the last term. Here and throughout this paper, my intention is not to label and attack individuals according to class, color, or sex; rather, I attempt to target a habit of thinking that arbitrarily invests (and accepts as natural) certain groups with the cultural authority and power to oppress others. Such thinking, of course, cuts across boundaries of class, color, and gender as does thinking which challenges the strategies of male hegemony I refer to later.

5 Sally Miller Gearhart, "If the Mortarboard Fits ... Radical Feminism in Academia," Learning Our Way: Essays in Feminist Education, eds. Charlotte Bunch and Sandra Pollack (Trumansburg, New York: The Crossing Press, 1983), 4, 13.

6 Ann Ferguson, "Feminist Teaching: A Practice Developed in Undergraduate 
Courses," Radical Teacher, 20, n.d.: 26.

7 Michael Ryan, "Deconstruction and Radical Teaching," Yale French Studies, 63 (1982): 45-58.

8 Paulo Freire, Pedagogy of the Oppressed, trans. Myra Bergman Ramos, (New York: Herder and Herder, 1970), 58.

9 Francis Maher, "Classroom Pedagogy and the New Scholarship on Women," Gendered Subjects, 32.

10 Elizabeth Spelman, "Combating the Marginalization of Black Women in the

Classroom," Gendered Subjects, 242.

11 Freire, 71.

12 Freire, 72.

13 Maher, 42.

14 Elaine Showalter coins and defines the word "gynocritics" (adopted from the French term la gynocritique) as the "type of feminist criticism . . . concerned with woman as writer-with woman as the producer of textual meaning, with the history, themes, genres, and structures of literature by women. Its subjects include the psychodynamics of female creativity; linguistics and the problem of a female language; the trajectory of the individual and collective female literary career; literary history; and of course, studies of particular writers and works." See her "Towards a Feminist Poetics," The New Feminist Criticism: Essays on Women, Literature and Theory, ed. Elaine Showalter (New York: Pantheon, 1985), 128.

While such projects are inherently attractive to gynocritics who are themselves women, I do not wish to suggest that being female is a prerequisite to being a gynocritic. Showalter's interest in separatism are well-known; but in my view, the more male scholars take up women's writing and history, the better, because this can only encourage a fuller, more accurate (re)vision of both literary and human history. An issue beyond the scope of this paper-one that is complex and deserving of discussion, I think - concerns the special problems and rewards embraced by male feminists.

15 I appropriate here and below the expression "anxiety of authorship" as well as the metaphors of "swerve," "disease," "infection in the sentence" from Sandra Gilbert and Susan Gubar, The Madwoman in the Attic: The Woman Writer and the Nineteenth-Century Literary Imagination (New Haven: Yale University Press, 1979). In this voluminous study which revises Harold Bloom's theory of literary paternity in relation to the especial condition of the nineteenth-century female who takes up the pen, Gilbert and Gubar's insistence on pathology is at times disturbing and often obsessive. Yet I find that the notion of anxiety and their concern with the debilitating effects of a literary heritage privileging fathers quite valid when considering the risks of traditional prose models.

16 "Wild zone" is another Showalterian term, á la Edwin Ardener, which denotes a female space of discourse outside and unlike that of the dominant and male order. "Feminist Criticism in the Wilderness," The New Feminist Criticism, 262. 